\title{
Biomimetic Apatite Deposition on Polymeric Microspheres Treated With a Calcium Silicate Solution
}

\author{
Isabel B. Leonor, ${ }^{1,2,3}$ Francisco Balas, ${ }^{4}$ Masakazu Kawashita, ${ }^{5}$ Rui L. Reis, ${ }^{1,2}$ \\ Tadashi Kokubo, ${ }^{3}$ Takashi Nakamura ${ }^{6}$
}

${ }^{1}$ 3B's Research Group-Biomaterials, Biodegradables and Biomimetics, Department of Polymer Engineering, University of Minho, Headquarters of the European Institute of Excellence on Tissue Engineering and Regenerative Medicine, Guimarães, Portugal

2 PT Government Associated Laboratory, IBB-Institute for Biotechnology and Bioengineering, Guimarães, Portugal

${ }^{3}$ Department of Biomedical Sciences, College of Life and Health Sciences, Chubu University, Aichi 487-8501, Japan

${ }^{4}$ Department of Chemical Engineering and Environmental Technologies, University of Zaragoza, 50009 Zaragoza, Spain

${ }^{5}$ Department of Biomedical Engineering, Graduate School of Biomedical Engineering, Tohoku University, Aoba, Sendai 980-8579, Japan

${ }^{6}$ Department of Orthopaedic Surgery, Faculty of Medicine, Kyoto University, Sakyo-ku, Kyoto 606-8506, Japan

\begin{abstract}
Bioactive polymeric microspheres can be prepared by means of coating them with a calcium silicate solution and subsequently soaking in a simulated body fluid (SBF). Such combination should allow for the development of bioactive microspheres for several applications in the medical field including tissue engineering carriers. Four types of polymeric microspheres, with different sizes, were used in this work: (i) ethylene-vinyl alcohol copolymer (20-30 $\mu \mathrm{m})$, (ii) polyamide 12 with $10 \%$ magnetite $(100 \mu \mathrm{m})$, (iii) polyamide $12(10-30 \mu \mathrm{m})$ and (iv) polyamide $12(300 \mu \mathrm{m})$. These microspheres were soaked in a calcium silicate solution at $36.5^{\circ} \mathrm{C}$ for various periods of time under different conditions. Afterwards, they were dried in air at 60 and $100^{\circ} \mathrm{C}$ for $24 \mathrm{hr}$. Then, the samples were soaked in SBF for 1, 3, and 7 days. Fourier transformed infrared spectroscopy, thin-film X-ray diffraction, and scanning electron microscopy showed that after the calcium silicate treatment and the subsequent soaking in SBF, the microspheres successfully formed an apatite layer on their surfaces in SBF within $\mathbf{7}$ days due to the formation of silanol groups, which are effective for apatite formation. (C) 2009 Wiley Periodicals, Inc. J Biomed Mater Res Part B: Appl Biomater 91B: 239-247, 2009
\end{abstract}

Keywords: biomimetics; calcium silicate; polymeric microspheres; silanol (Si-OH); sol-gel processes

\section{INTRODUCTION}

Hydroxyapatite (HA), one of the major constituent of the bone and teeth, has been often designated as osteointegrat-

Correspondence to: I. Leonor (e-mail: belinha@dep.uminho.pt)

Contract grant sponsor: Portuguese Foundation for Science and Technology (FCT); Contract grant number: SFRH/BD/9031/2002

Contract grant sponsor: European Union STREP Project HIPPOCRATES; Contract grant number: NMP3-CT-2003-505758

Contract grant sponsor: European NoE EXPERTISSUES; Contract grant number: NMP3-CT-2004-500283

(C) 2009 Wiley Periodicals, Inc. ing and/or osteoconductive (i.e. bioactive) material. ${ }^{1-3}$ During the last few decades, this bioactive ceramic, in different forms, has been used clinically due to its good biocompatibility $^{2,3}$ and efficacy in promoting biointegration for implants in hard and soft tissue. ${ }^{2}$ Moreover, the analysis of the interface between bone and bioactive implant is morphologically comparable to that of cement lines found naturally in bone remodeling sites, and this interfacial layer is formed on chemically active surface of the biomaterials, which is one of the key features in the bonding zone. ${ }^{4}$

As it was mentioned above, due to their physiochemical and biological properties, as well as the excellent 
osteoconductive ability, recently calcium phosphates, such as HA, $\beta$-tri-calcium phosphate, have been considered as a potential material to be used as a tissue engineering carrier system. ${ }^{3,5}$

Normally, these ceramics are used in powder and block form for bone repair. ${ }^{6}$ Even the use the ceramic granules has an advantage of its adaptability to the shape of bone defect, it has a drawback, which is the migration of the particles from the implant site before the tissue ingrowth starts and the simultaneous lost of the delivery of the therapeutic molecules into the defect site. ${ }^{6,7}$ In the block form, it is difficult to fill the irregular surface of bone defects and to reconstruct the shape of bones completely. ${ }^{8}$

To overcome these disadvantages, it is necessary to find a new bioactive material for bone repair which at same time can release a bioactive agent in situ for treatment and prevention of bone infection. Furthermore, when combining these properties with the advantageous bone-bonding properties of calcium-phosphate coating, there is a distinct potential for this material to be used as controlled release systems of either bone-acting drugs or growth factors. In principle, these systems would be able to bond to bone and at the same time act as drug release systems.

Polymeric microspheres are widely used for several applications in the biomedical field, namely as carriers of biologically active agents (anticancer drugs, biologically active amines, and antibiotics, antimicrobial agents). ${ }^{6-15}$ Besides, it is believed that the use of microspheres can lead to more versatile applications in bone repair and might be useful for designing injectable biomaterial systems. ${ }^{12}$ Also, ferrimagnetic microspheres are expected to be useful as thermoseeds for hyperthermic treatment of bone tumors. ${ }^{16-20}$

In the development of new biomaterials for bone regeneration, surface properties must be modified ideally to mimic the tissue to be replaced. Furthermore, a strong bonding between the host bone and the osteoconductive surface is also required. If it is possible to coat the microspheres with an apatite layer, they can be used for bone repair and at same time release an antibiotic in situ for treatment and prevention of bone infection. In addition, if the microspheres contain ferrimagnetic materials, they are expected to be able to treat tumors in deep regions, especially in bone by a heat generation under alternating magnetic field. As result, the heat damage to soft tissue around the bone can be prevented by using these microspheres.

It has been reported ${ }^{21-23}$ that silanol $(\mathrm{Si}-\mathrm{OH})$ groups on polymeric materials can induce apatite formation in acellular simulated body fluids (SBF) with ion concentrations nearly equal to those of the human blood plasma. Also, it was demonstrated that when an ethylene-vinyl alcohol copolymer $(\mathrm{EVOH})$ was treated with silane coupling agent and calcium silicate solution and then soaked in SBF a smooth and uniform bonelike apatite layer was able to be formed on the surface of EVOH. ${ }^{24}$ However, none have been succeed in uniform coating apatite on polymeric microspheres. The aim of this study is to form $\mathrm{Si}-\mathrm{OH}$ groups onto polymeric microspheres by means of soaking them in a calcium silicate solution, to obtain bioactive microspheres for bone repair that are able to release in situ an antibiotic for treatment and prevention of bone infection. The same concept can then be applied to the release of other relevant bioactive agents, including different drugs and growth factors.

\section{MATERIALS AND METHODS}

\section{Materials}

Four types of microspheres with different sizes were used as substrates: (i) ethylene-vinyl alcohol copolymer (EVOH; 20-30 $\mu \mathrm{m}$ ), (ii) polyamide 12 with $10 \%$ magnetite (PA 12 $\left.\left(10 \% \mathrm{Fe}_{3} \mathrm{O}_{4}\right) ; 100 \mu \mathrm{m}\right)$, (iii) polyamide 12 (PA 12; 10-30 $\mu \mathrm{m}$ ), (iv) polyamide 12 (PA 12; $300 \mu \mathrm{m}$ ). These microspheres were kindly supplied by Trial Corporation, Kanagawa, Japan.

\section{Calcium Silicate Solution Treatment}

Tetraethoxysilane (TEOS: $\left.\mathrm{Si}\left(\mathrm{OC}_{2} \mathrm{H}_{5}\right)_{4}\right)$, ultra-pure water, ethyl alcohol $\left(\mathrm{C}_{2} \mathrm{H}_{5} \mathrm{OH}\right), 1.0 \mathrm{M}$ - $\mathrm{HCl}$ aqueous solution and calcium chloride $\left(\mathrm{CaCl}_{2}\right)$ were mixed for $10 \mathrm{~min}$ at $0^{\circ} \mathrm{C}$ to prepare calcium silicate solution with two different molar ratios as it is shown in the Table I.

The microspheres were immediately soaked in $10 \mathrm{~mL}$ of calcium silicate solution under two conditions: (i) $\mathrm{H}_{2} \mathrm{O}$ / TEOS $=4 / 1$ for $2 \mathrm{hr}$ (condition I) and (ii) $\mathrm{H}_{2} \mathrm{O} / \mathrm{TEOS}=$ $2 / 1$ that has been aged for $168 \mathrm{hr}$ before using, for $5 \mathrm{~min}$ (condition II). Then, the flasks were placed in a shaker incubator at $36.5^{\circ} \mathrm{C}$ and 120 strokes $/ \mathrm{min}$. The specimen were filtered and then dried in air at 60 and $100^{\circ} \mathrm{C}$ for $24 \mathrm{hr}$.

\section{Soaking in Simulated Body Fluid}

The obtained microspheres were soaked in $20 \mathrm{~mL}$ of a SBF $(\mathrm{SBF})^{21}$ with ion concentrations $\left(\mathrm{Na}^{+} 142.0, \mathrm{~K}^{+} 5.0, \mathrm{Ca}^{2+}\right.$ 2.5, $\mathrm{Mg}^{2+} 1.5, \mathrm{Cl}^{-} 147.8, \mathrm{HCO}_{3}^{-} 4.2, \mathrm{HPO}_{4}^{2-} 1.0, \mathrm{SO}_{4}^{2-}$ $0.5 \mathrm{mM}$ ) nearly equal to those of the human blood plasma in $70 \mathrm{~mL}$ polystyrene sterile flasks at $36.5^{\circ} \mathrm{C}$ for different periods up to 7 day. The SBF was prepared by dissolving reagent-grade chemicals of $\mathrm{NaCl}, \mathrm{NaHCO}_{3}, \mathrm{KCl}$, $\mathrm{K}_{2} \mathrm{PO}_{4} \cdot 3 \mathrm{H}_{2} \mathrm{O}, \mathrm{MgCl}_{2} \cdot 6 \mathrm{H}_{2} \mathrm{O}, \mathrm{CaCl}_{2}$ and $\mathrm{NaSO}_{4}$ into distilled water, and buffered at $\mathrm{pH} 7.40$ with tris-hydroxymethylaminomethane $\left(\left(\mathrm{CH}_{2} \mathrm{OH}\right)_{3} \mathrm{CNH}_{3}\right)$ and $1.0 \mathrm{M}$ hydrochloric acid at $36.5^{\circ} \mathrm{C}$. The flasks were put in an incubator shacked at 120 strokes/min. After soaking, the specimens were

TABLE I. Chemical Compositions (Molar Ratio) of Calcium Silicate Solution Used in This Study

\begin{tabular}{lcccccc}
\hline & TEOS & $\mathrm{H}_{2} \mathrm{O}$ & $\mathrm{C}_{2} \mathrm{H}_{5} \mathrm{OH}$ & $\mathrm{HCl}$ & $\mathrm{CaCl}_{2}$ & $\mathrm{H}_{2} \mathrm{O} / \mathrm{TEOS}$ \\
\hline Condition I & 1.0 & 4.0 & 4.0 & 0.014 & 0.20 & $4.0 / 1.0$ \\
Condition II & 1.0 & 2.0 & 1.0 & 0.014 & 0.20 & $2.0 / 1.0$ \\
\hline
\end{tabular}



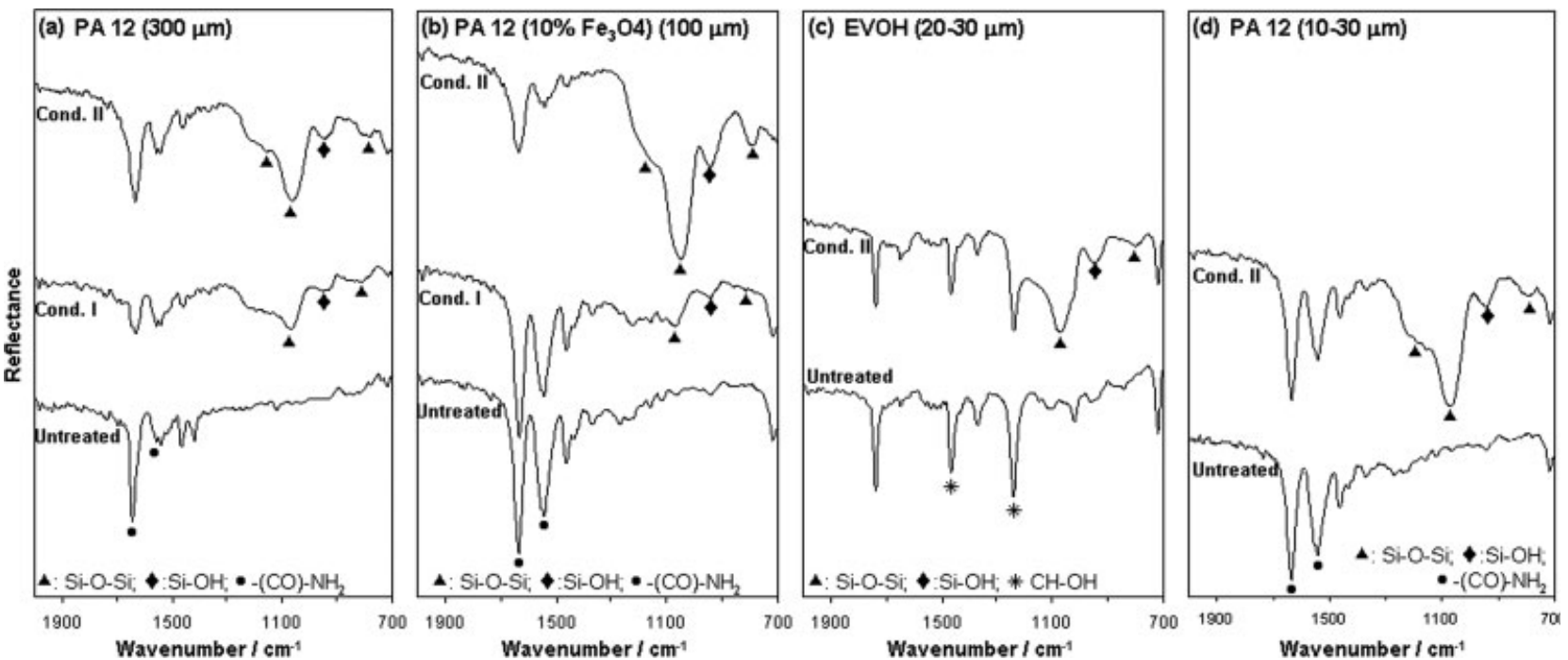

Figure 1. FT-IR spectra of the surfaces of PA $12(300 \mu \mathrm{m})(\mathrm{a}), \mathrm{PA} 12\left(10 \% \mathrm{Fe}_{3} \mathrm{O}_{4}\right)$ (b) $(100 \mu \mathrm{m})$, EVOH $(20-30 \mu \mathrm{m})(\mathrm{c})$ and PA $12(10-30 \mu \mathrm{m})(\mathrm{d})$ microspheres, which were coated with a calcium silicate layer under condition I (2 hr of immersion) or II (5 min of immersion in the solution that has aged for $168 \mathrm{hr}$ before using).

removed from SBF, washed with distilled water and dried in a clean bench.

\section{Analyses of Surface and SBF}

Surfaces of polymeric microspheres, before and after the solution treatments, were analyzed by field-emission scanning electron microscopy (FE-SEM: S-4700, Hitachi Ltd., Japan) attached with energy-dispersive electron X-ray spectroscopy (EDS: EMAX-7000, Horiba Ltd., Japan), thin film X-ray diffraction (TF-XRD: RINT2500, Rigaku Co., Japan) and Fourier transform attenuated total reflectance infrared spectroscopy (FT-IR: Magna 860, Nicolet Co.). Elemental concentrations of the SBF, before and after soaking the polymeric microspheres, were measured using inductively coupled plasma atomic emission spectrometry (ICP: SPS1500VR, Seiko Instruments Inc., Japan).

\section{RESULTS}

\section{Surface Structural Changes of the Microspheres After the Calcium Silicate Treatment}

Figure 1 show the FT-IR spectra of the surfaces of the microspheres, which were subjected to the calcium silicate treatment. For the untreated microspheres, in the IR spectrum of the surfaces of PA $12(300 \mu \mathrm{m})$, PA $12(10 \%$ $\left.\mathrm{Fe}_{3} \mathrm{O}_{4}\right)(100 \mu \mathrm{m})$, and PA $12(10-30 \mu \mathrm{m})$ it was possible to identify the typical bands of the amide group (amide I) (around $1634 \mathrm{~cm}^{-1}$ ) assigned to $\mathrm{C}=\mathrm{O}$ stretching vibration and around $1540 \mathrm{~cm}^{-1}$ (amide II) assigned to NH deformation and to $\mathrm{N}-\mathrm{C}=\mathrm{O}$ symmetric stretching vibration [Figure $1(\mathrm{a}, \mathrm{b})$ and $1(\mathrm{~d})]$. In turn, the bands appearing at 1462 and $1236 \mathrm{~cm}^{-1}$ in the EVOH $(20-30 \mu \mathrm{m})$ spectrum [Figure 1(c)] correspond to the $\mathrm{OH}$ deformation and $\mathrm{C}-\mathrm{O}$ stretching vibration modes of the secondary alcohols, respectively.

All the investigated microspheres could be a quite successfully coated with a calcium silicate layer under different conditions. After the calcium silicate treatment, the reflection peaks of $\mathrm{Si}-\mathrm{OH}$ groups, which are typically observed for a silica gel, and siloxane (Si-O-Si) bonds were detected in the FT-IR spectra. ${ }^{25}$ The presence of Si$\mathrm{OH}$ groups and $\mathrm{Si}-\mathrm{O}-\mathrm{Si}$ bond suggests that TEOS was successfully hydrolyzed to form $\mathrm{Si}-\mathrm{OH}$ groups and polycondensed to form Si-O-Si network. The intensity of Si-O-Si as well as $\mathrm{Si}-\mathrm{OH}$ peak was more pronounced for condition II than condition I. This increase, specially the $\mathrm{Si}-\mathrm{O}-\mathrm{Si}$ bond, is usually associated with a higher porosity of the coating. ${ }^{26-28}$ Moreover, the intensity of a broad IR band between 3360 and $3336 \mathrm{~cm}^{-1}$, which is ascribed to hydroxyl groups, becomes stronger in the condition II indicating that TEOS was completely hydrolyzed into $\mathrm{Si}-\mathrm{OH}$ groups.

\section{Surface Structural Changes of the Microspheres in SBF}

After soaking in SBF it was performed FT-IR analysis to characterize the chemical structure of the obtained calcium phosphate under the different conditions. Figure 2 show FT-IR spectra of the surface of the microspheres, which were subjected to the calcium silicate treatment under condition I or II and subsequently soaked in SBF up to 7 days.

After soaking in SBF for 1 day, the reflection peak of phosphate group $\left(\mathrm{PO}_{4}^{3-}\right.$ ) (around 1028 and $1012 \mathrm{~cm}^{-1}$ ) was observed for all microspheres under condition II [Figure $2(\mathrm{a} 2, \mathrm{~b} 2)$ and $2(\mathrm{c}, \mathrm{d})] \cdot{ }^{29}$ As the soaking time in SBF increase, the phosphate band becomes sharper and a well 

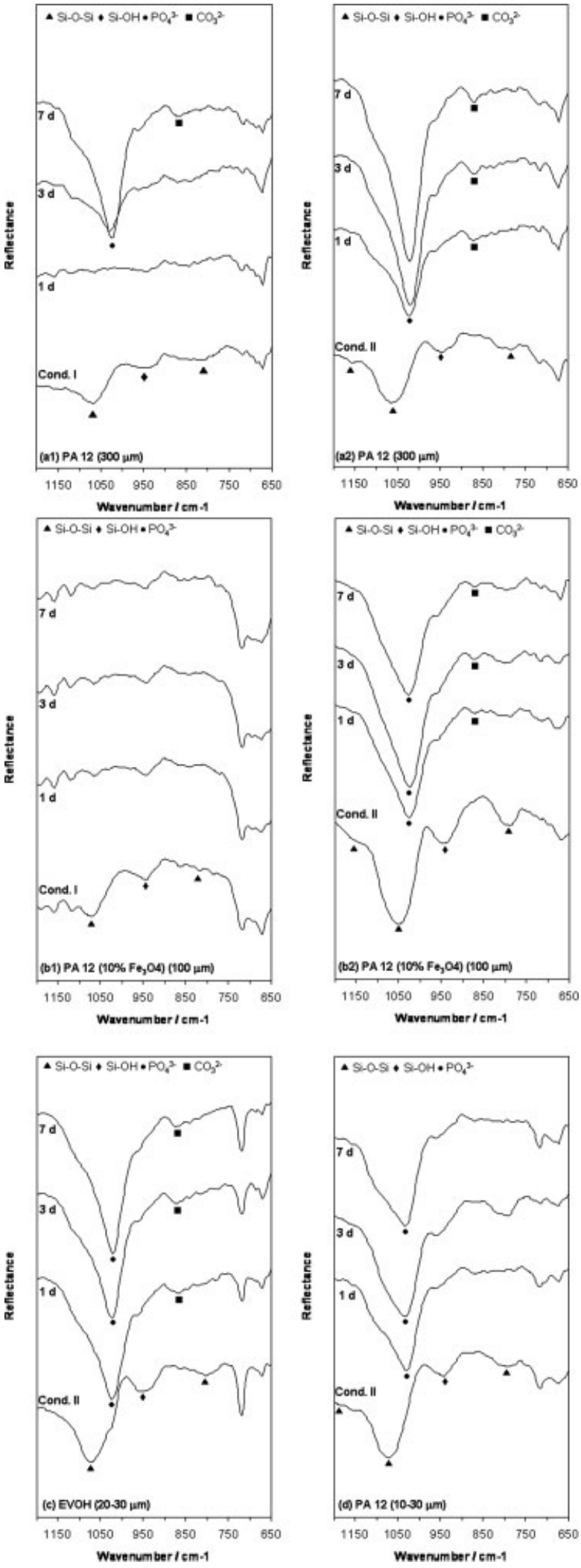

Figure 2. FT-IR spectra of the surfaces of PA $12(300 \mu \mathrm{m})(\mathrm{a}), \mathrm{PA} 12$ $\left(10 \% \mathrm{Fe}_{3} \mathrm{O}_{4}\right)(100 \mu \mathrm{m})(\mathrm{b}), \mathrm{EVOH}(20-30 \mu \mathrm{m})$ (c) and PA $12(10-30$ $\mu \mathrm{m})(\mathrm{d})$ microspheres, which were treated with a calcium silicate solution under condition I ( $2 \mathrm{hr}$ of immersion) or II (5 min of immersion in the solution that has aged for $168 \mathrm{hr}$ before using) and subsequently soaked in SBF for 1,3 , and $7 \mathrm{~d}$. defined band. However, for PA $12(300 \mu \mathrm{m})$ under condition I it was only possible to detect the phosphate group after 3 days in SBF [Figure 2(a1)]. As for PA 12 (10\% $\left.\mathrm{Fe}_{3} \mathrm{O}_{4}\right)(100 \mu \mathrm{m})$ under the condition I no phosphate groups were possible detected up to 7 days in SBF.

Moreover, a reflection peak associated with carbonate substitution around $864 \mathrm{~cm}^{-1}$ was observed in the collected spectra for PA $12(300 \mu \mathrm{m})$ under condition I and II and for PA $12\left(10 \% \mathrm{Fe}_{3} \mathrm{O}_{4}\right)(100 \mu \mathrm{m})$ and EVOH $(20-30 \mu \mathrm{m})$ under condition II (Figure 2).

Figure 3 shows TF-XRD patterns of the surfaces of PA $12(300 \mu \mathrm{m})$, PA $12\left(10 \% \mathrm{Fe}_{3} \mathrm{O}_{4}\right)(100 \mu \mathrm{m}), \mathrm{EVOH}(20$ $30 \mu \mathrm{m})$, and PA $12(10-30 \mu \mathrm{m})$ microspheres, which were coated with a calcium silicate layer under condition I or II and subsequently soaked in SBF up to 7 days.

For both conditions I and II, the structure of all microspheres was not changed even after the coating, giving the same diffraction patterns as the untreated microspheres, which means that the microspheres were completely coated with a calcium silicate layer. In the case of PA $12(10 \%$ $\mathrm{Fe}_{3} \mathrm{O}_{4}$ ) microspheres, the diffraction peak of maghemite phase $\left(\gamma-\mathrm{Fe}_{2} \mathrm{O}_{3}\right.$-ASTM JCPDS 25-1402) disappeared after the calcium silicate treatment but the diffraction peak of magnetite phase $\left(\mathrm{Fe}_{3} \mathrm{O}_{4}\right.$ - ASTM JCPDS 11-0614) was still detected, although its intensity was significantly reduced [Figure 3(c)]. It can be seen from Figure 3 that after 7 days in SBF, the TF-XRD patterns showed several diffraction maxima that can be assigned to an apatite-like phase (ASTM JCPDS 9-432), for both conditions and for all materials, although the intensity of apatite peaks was not so high in some cases [Figure 3(a,d)].

However, for condition I, only the microspheres PA 12 $(300 \mu \mathrm{m})$ formed an apatite layer after 7 days in SBF, as it is shown in Figure 3. These differences might be attributed to a further progress of hydrolysis and polycondensation of TEOS in the calcium silicate solution due to a long aging period of $168 \mathrm{hr}$ in condition II.

Figures 4-6 shows FE-SEM images and the EDS spectra of the surfaces of microspheres, untreated and treated with calcium silicate solution under the condition I and II, and then soaked in SBF for 1, 3, and 7 days.

After the soaking in the calcium silicate solution treatment, a smooth layer appeared on the surface of microspheres. This layer should be a calcium silicate layer, according to the FT-IR and EDS results shown in the Figures 1 and 4-6. The calcium silicate layer obtained under the condition I was compact and presents a thickness approximately $1.5 \mu \mathrm{m}$ and $240 \mathrm{~nm}$ [Figures 4(a) and 5(a)]. As for the condition II, the calcium silicate layer had a porous structure and the thickness was very high, around $4.5 \mu \mathrm{m}$ and $1 \mu \mathrm{m}$ [Figures 4(b) and 5(b)].

When the PA $12(300 \mu \mathrm{m})$ and PA $12\left(10 \% \mathrm{Fe}_{3} \mathrm{O}_{4}\right)$ $(100 \mu \mathrm{m})$ microspheres, which were coated with a calcium silicate layer under condition I, were soaked in SBF up to 7 days, only the PA $12(300 \mu \mathrm{m})$ microspheres could be completely covered with a uniform apatite layer within 

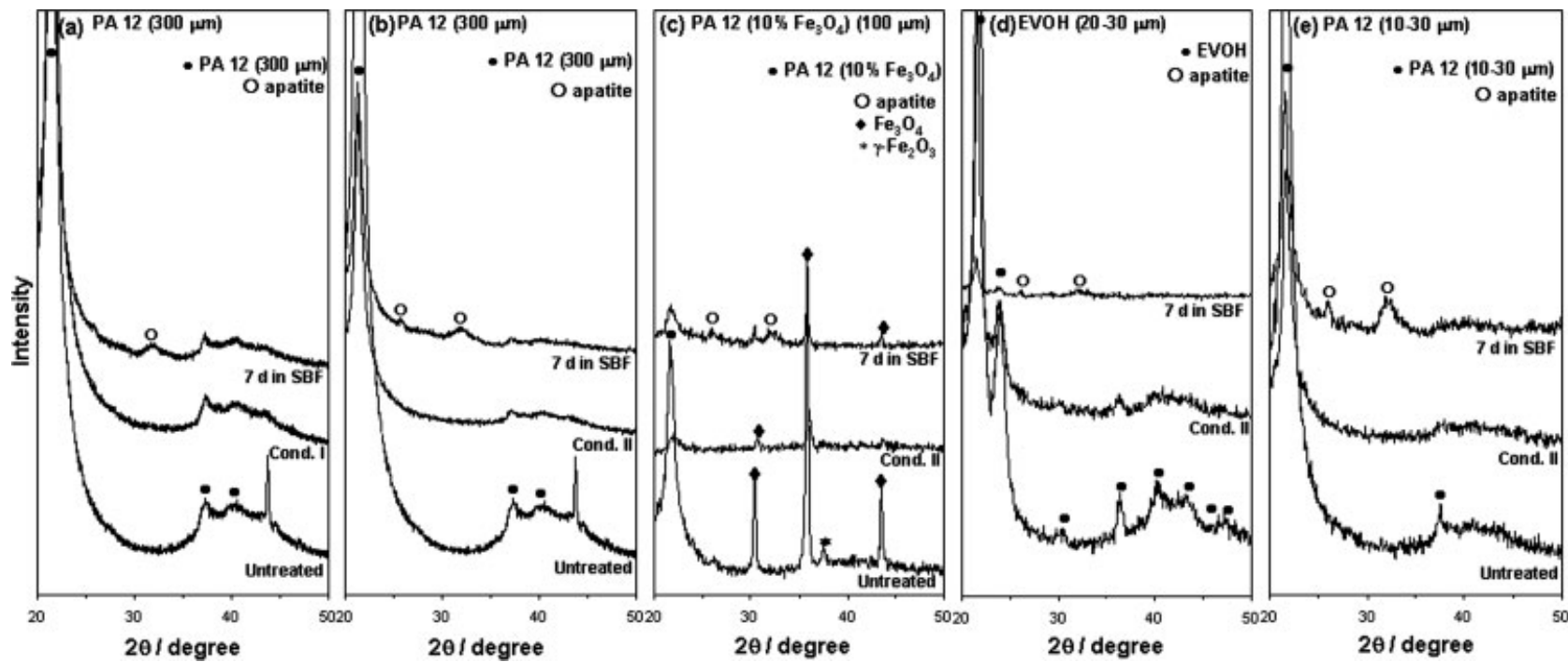

Figure 3. TF-XRD patterns of the surfaces of PA $12(300 \mu \mathrm{m})(\mathrm{a}, \mathrm{b}), \mathrm{PA} 12\left(10 \% \mathrm{Fe}_{3} \mathrm{O}_{4}\right)(100 \mu \mathrm{m})$ (c), EVOH $(20-30 \mu \mathrm{m})(\mathrm{d})$ and PA $12(10-30 \mu \mathrm{m})(\mathrm{e})$ microspheres, which were coated with a calcium silicate layer under condition I ( $2 \mathrm{hr}$ of immersion) or II (5 min of immersion in the solution that has aged for $168 \mathrm{hr}$ before using) and subsequently soaked in SBF for 7 days.

3 days [Figure 4(a)]. However even after 7 days in SBF, this layer was very fine (around 1.5 and $1 \mu \mathrm{m}$ ) and not dense, which was in agreement with the TF-XRD in Figure 3(a). For PA $12\left(10 \% \mathrm{Fe}_{3} \mathrm{O}_{4}\right)(100 \mu \mathrm{m})$ the formation of an apatite layer was not observed even after 7 days in SBF as it is shown in the Figure 5(a).

For condition II, all the investigated microspheres showed an ability to induce the formation of an apatite layer within 1 day in SBF as it is shown in the Figures 4(b), 5(b), 6(a,b). Moreover, at higher magnifications it is evidenced a finer structure where needle-like crystals are agglomerated.

For PA $12(300 \mu \mathrm{m})$ microspheres, it can be seen the increase of thickness of the apatite coating as function of soaking time in SBF, it goes from $700 \mathrm{~nm}$ to $1 \mu \mathrm{m}$ [Figure 4(b)].

However, for the PA $12\left(10 \% \mathrm{Fe}_{3} \mathrm{O}_{4}\right)(100 \mu \mathrm{m})$ the apatite coating was not so uniform and from the SEM micrographs it can be observed that there is no significant differences between the periods of soaking in SBF in terms of thickness of the apatite layer, that is appears to be too thin [Figure 5(b)].

For EVOH $(20-30 \mu \mathrm{m})$, the formation of an apatite layer was observed after the calcium silicate treatment in condition II and the subsequent soaking in SBF for 1 day. In the Figure 6(a) it can be seen that the apatite layer was very dense and compact, a thickness is $\sim 1.5 \mu \mathrm{m}$. On the other hand, an aggregation of these microspheres was (a)

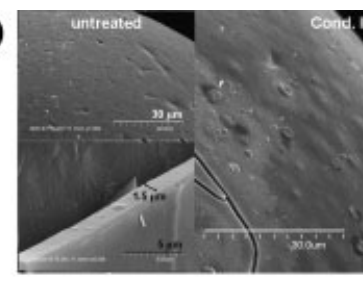

(b)

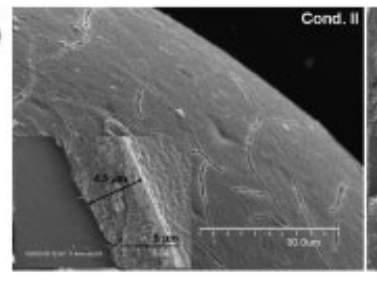

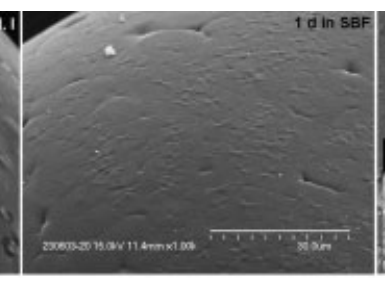
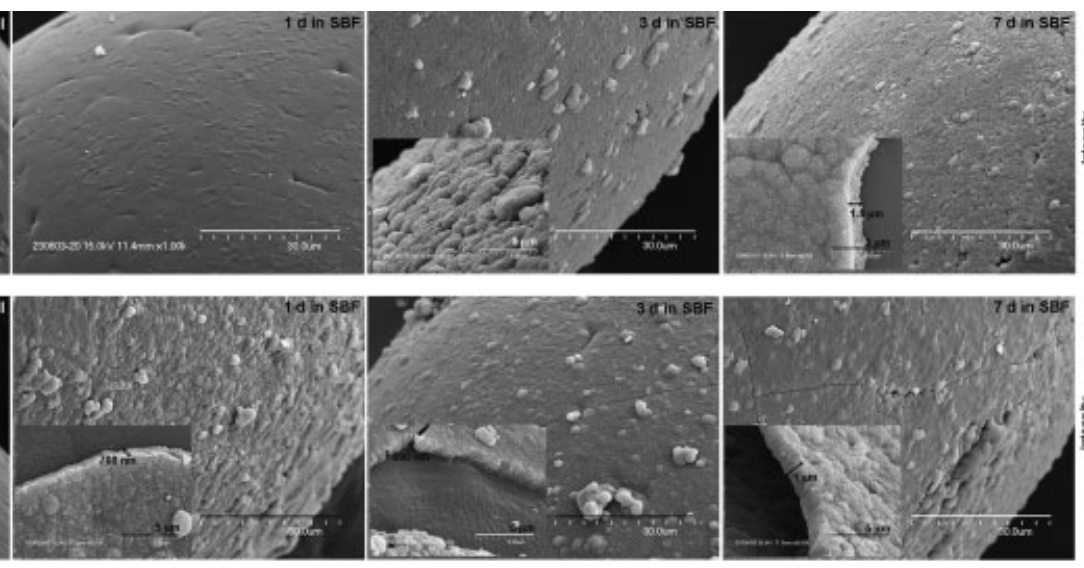
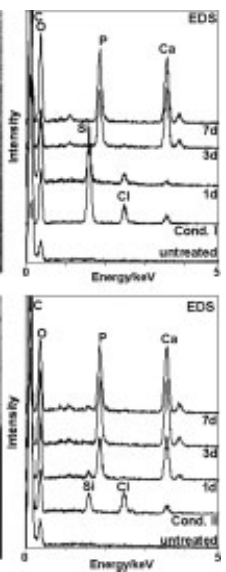

Figure 4. SEM-EDS profiles of the surface of PA $12(300 \mu \mathrm{m})$ microspheres, which were coated with a calcium silicate layer under condition I (2 hr of immersion) (a) or II (5 min of immersion in the solution that has aged for $168 \mathrm{hr}$ before using) (b) and subsequently soaked in SBF for 1,3 , and 7 days. (Arrows in the micrographs indicate the thickness of the calcium silicate and apatite coatings). 
(a)
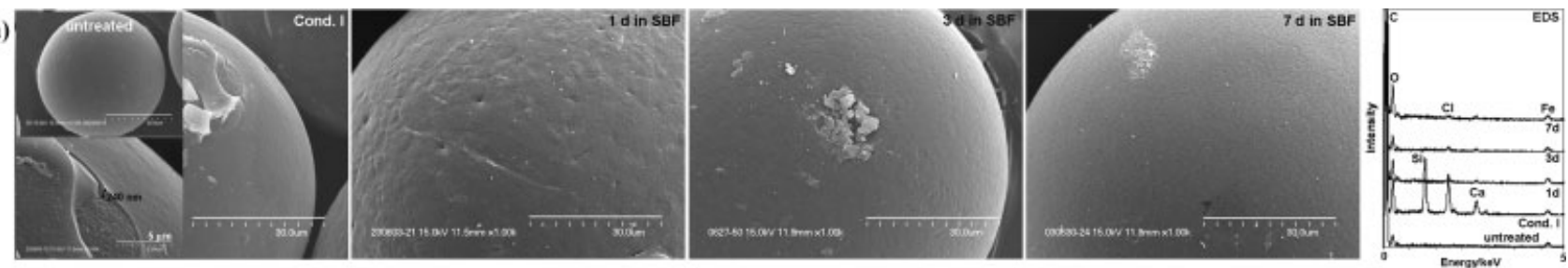

(b)
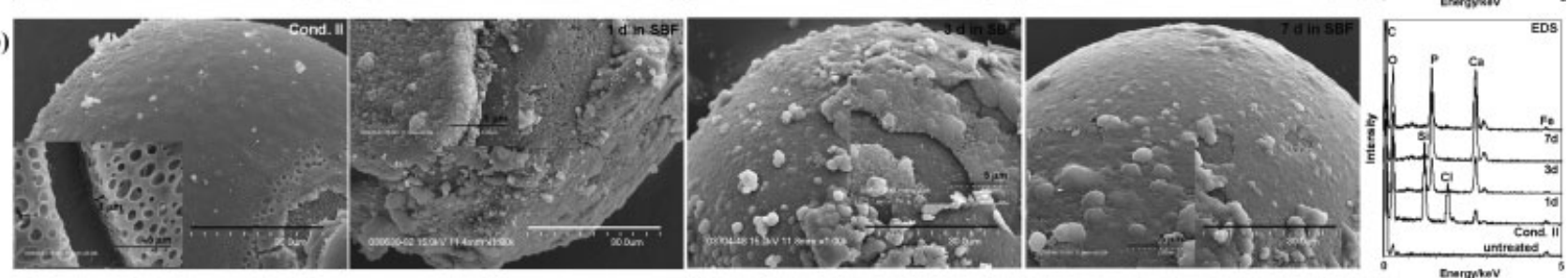

Figure 5. SEM-EDS profiles of the surface of PA $12\left(10 \% \mathrm{Fe}_{3} \mathrm{O}_{4}\right)(100 \mu \mathrm{m})$ microspheres, which were coated with a calcium silicate layer under condition I (2 hr of immersion) (a) or II (5 min of immersion in the solution that has aged for $168 \mathrm{hr}$ before using) (b) and subsequently soaked in SBF for 1,3 , and 7 days. (Arrows in the micrographs indicate the thickness of the calcium silicate coating).

found to occur quite easily both in a calcium silicate solution as well as in SBF as it is shown in the Figure 6(a). For PA $12(10-30 \mu \mathrm{m})$ microspheres, the apatite layer was not as dense and has a thickness of $1 \mu \mathrm{m}$, comparing with the all microspheres used [Figures 4(b), 5(b) and 6(b)].

By EDS measurement, it was detected an appreciable quantity of silicon $(\mathrm{Si})$, chlorine $(\mathrm{Cl})$ and calcium $(\mathrm{Ca})$ was detected on the surface of all microspheres after the calcium silicate treatment under the conditions I and II (Figures 4, 5 and 6). It can be observed that the peak intensities of $\mathrm{Ca}$ and $\mathrm{Si}$ differ from the condition I and II, and also from the size of the microspheres. In the case of PA $12\left(10 \% \mathrm{Fe}_{3} \mathrm{O}_{4}\right)$ microspheres after the calcium silicate treated under the condition I or II, the EDS spectra show a signal of iron (Fe) (Figure 5) that is in good agreement with the detection of magnetite $\left(\mathrm{Fe}_{3} \mathrm{O}_{4}\right)$ and maghemite $\left(\mathrm{Fe}_{2} \mathrm{O}_{3}\right)$ in TF-XRD patterns [Figure 3(c)].

After soaking in SBF for 3 days, an appreciable amount of calcium $(\mathrm{Ca})$ and phosphorus $(\mathrm{P})$ was detected on the surface of the PA $12(300 \mu \mathrm{m})$ microspheres which were treated with a calcium silicate solution under the condition I [Figure 4(a)]. When the microspheres were treated with a calcium silicate solution under the condition II, after only 1 day in SBF, a significant quantity of $\mathrm{Ca}$ and $\mathrm{P}$ was detected [Figure 4(b)]. The intensity of $\mathrm{Ca}$ and $\mathrm{P}$ peaks increased significantly with increasing soaking time in SBF.

As for PA $12\left(10 \% \mathrm{Fe}_{3} \mathrm{O}_{4}\right)$ microspheres, only under the condition II, a strong signal ascribed to $\mathrm{P}$ and $\mathrm{Ca}$ was detected after 1 day in SBF. Also, for the other microspheres, EVOH and PA $12(10-30 \mu \mathrm{m})$, which were also

(a)
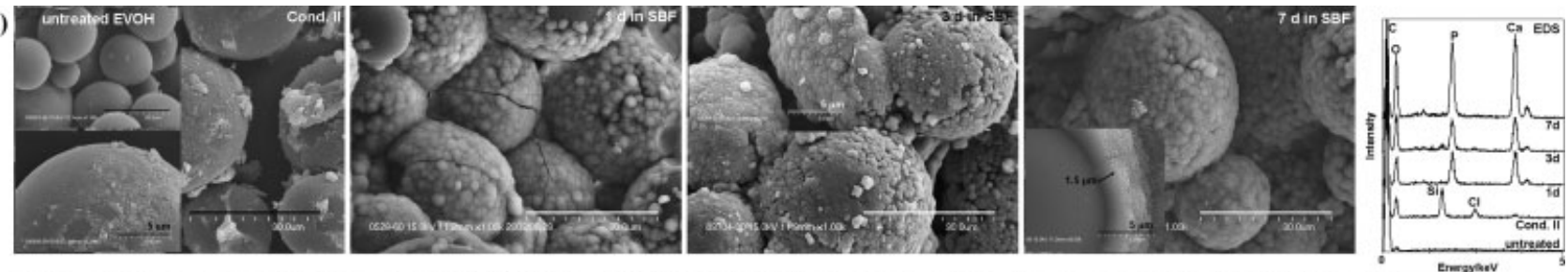

(b)
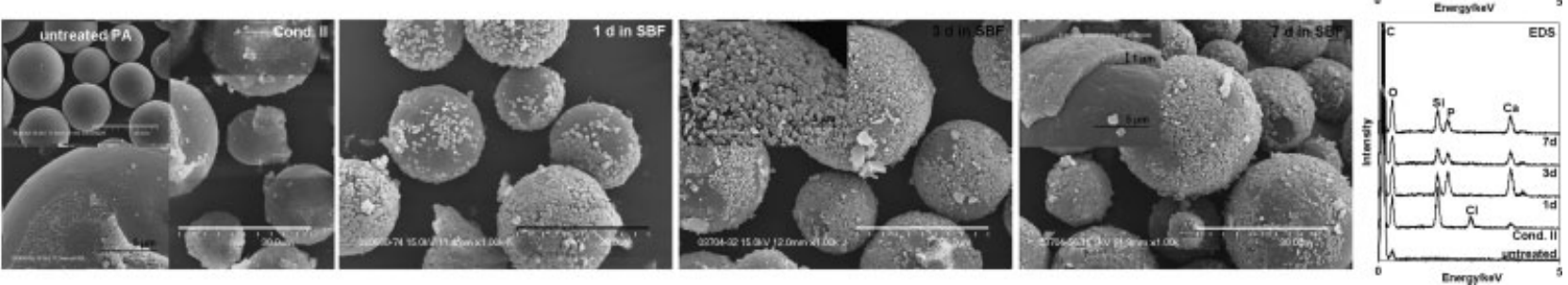

Figure 6. SEM-EDS profiles of the surface of EVOH $(20-30 \mu \mathrm{m})(\mathrm{a})$ and PA $12(10-30 \mu \mathrm{m})(\mathrm{b})$ microspheres, which were coated with a calcium silicate layer under condition II (5 min of immersion in the solution that has aged for $168 \mathrm{hr}$ before using) and subsequently soaked in SBF for 1, 3, and 7 days. (Arrows in the micrographs indicate the thickness of the calcium silicate and apatite coatings). 

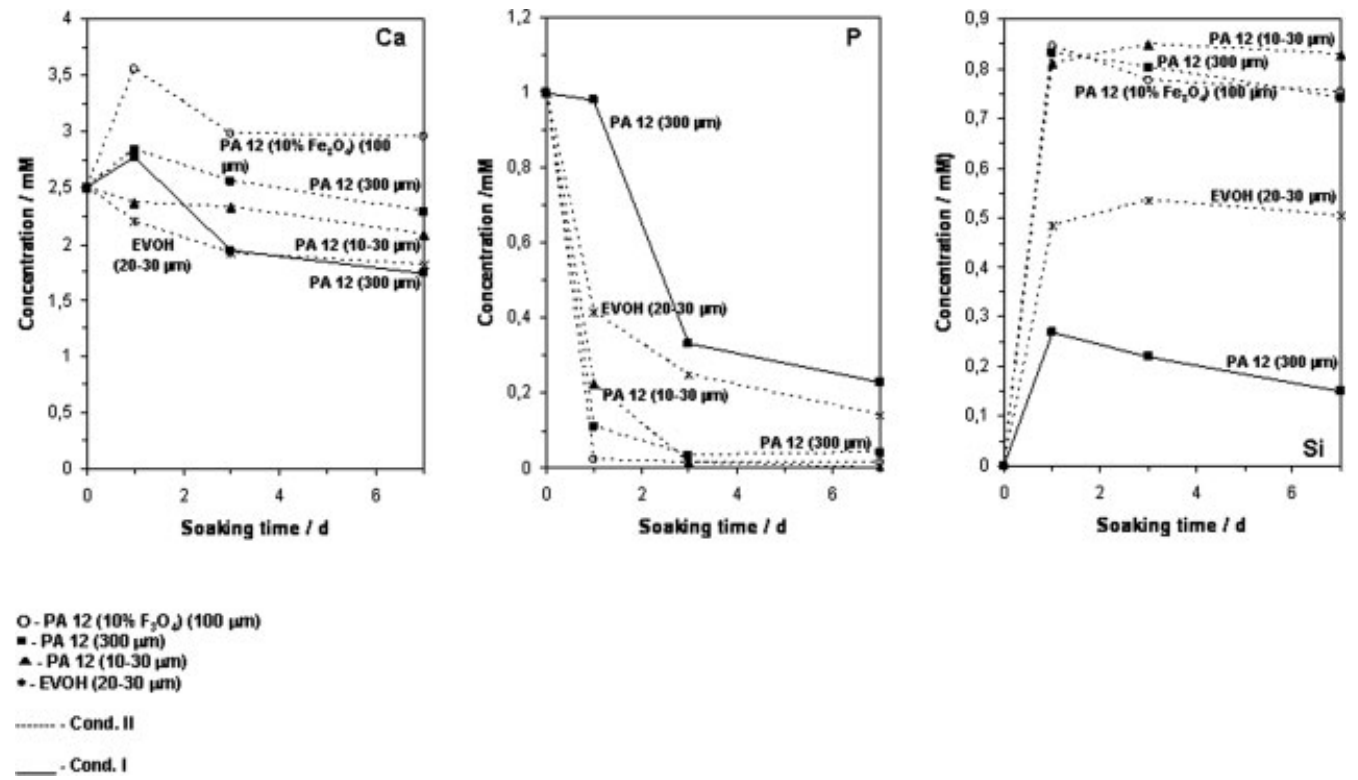

Figure 7. Changes in $\mathrm{Ca}, \mathrm{P}$ and $\mathrm{Si}$ concentration of the SBF with soaking time of the PA 12 (300 $\mu \mathrm{m})(\square)$, PA $12\left(10 \% \mathrm{Fe}_{3} \mathrm{O}_{4}\right)(100 \mu \mathrm{m})(\mathrm{O})$, EVOH $(20-30 \mu \mathrm{m})\left(^{*}\right)$ and PA $12(10-30 \mu \mathrm{m})(\boldsymbol{\Delta})$ microspheres, which were coated with a calcium silicate layer under condition I (-)or II (---).

coated under the condition II, it was detected the presence of the $\mathrm{Ca}$ and $\mathrm{P}$ elements after only 1 day in SBF [Figure $6(\mathrm{a}, \mathrm{b})]$. As the soaking time in SBF increased, the intensity of $\mathrm{Ca}$ and $\mathrm{P}$ signals increased significantly. However, for PA $12(10-30 \mu \mathrm{m})$ microspheres treated with a calcium silicate solution under condition II, the signal of the $\mathrm{Ca}$ and $\mathrm{P}$ elements was detected after 1 day in SBF, although their intensity was lower even after 7 days in SBF and also, the signal of $\mathrm{Si}$ continues to be detected as it can be seen in the Figure 6(b). From the EDS and FT-IR results, it was found that a calcium silicate layer, rich in $\mathrm{Ca}$ ions and $\mathrm{Si}$ $\mathrm{OH}$ groups, was formed on all the microspheres. These results are in good agreement with ones obtained from the TF-XRD analysis in Figure 3.

Figure 7 shows the concentrations of calcium, phosphorus and silicon in the SBF for PA $12(300 \mu \mathrm{m})$, PA 12 $\left(10 \% \quad \mathrm{Fe}_{3} \mathrm{O}_{4}\right)(100 \mu \mathrm{m})$, EVOH $(20-30 \mu \mathrm{m})$ and PA 12 (10-30 $\mu \mathrm{m})$ microspheres, which were coated with a calcium silicate layer under condition I or II, as result of soaking.

In the condition I and II, for the PA $12(300 \mu \mathrm{m})$ and PA $12\left(10 \% \quad \mathrm{Fe}_{3} \mathrm{O}_{4}\right)(100 \mu \mathrm{m})$ microspheres, the calcium concentration increased at an early stage due to the release of calcium ions from the surface of the specimen into SBF. As for the phosphorus concentration there was an accentuated decreased with increasing soaking time. Furthermore, an appreciable increase in silicon concentration was observed for all investigated microspheres. However, this increase was more accentuated for the microspheres which were coated with a calcium silicate layer under the condition II.

As the soaking time in SBF increase a decrease in calcium and phosphorus concentrations was observed due to the nucleation and growth of apatite on the microspheres.

\section{DISCUSSION}

As shown in the Figures 2, 3 and 4-6, the microspheres treated with calcium silicate solutions under the condition II formed apatite on their surfaces within 1 day of immersion in SBF. However, the apatite layer was very thin in almost all the microspheres and with further soaking in time in SBF the thickness didn't increase significantly, which can be due to the rapid consuming of phosphate ions from the SBF in first $24 \mathrm{hr}$ as it is shown in the Figure 7.

The presence of $\mathrm{Si}-\mathrm{OH}$ groups, effective in inducing apatite nucleation, ${ }^{22,23,30-33}$ on the microspheres before soaking in SBF is almost the same for both conditions (Figure 1). However, in terms of the structure of the calcium silicate coating, there were significant differences between the two conditions, which result from the molar ratios of $\mathrm{H}_{2} \mathrm{O}$ / TEOS in condition I and condition II which were 4/1 and $2 / 1$, respectively. When the $\mathrm{H}_{2} \mathrm{O} / \mathrm{TEOS}$ molar ratio of the calcium silicate solution decreased, the time for gelation also decreases. ${ }^{34}$ As a result, the calcium silicate solution in condition II gives a higher viscosity to form a uniform calcium silicate layer on the surfaces of the microspheres. Moreover, the calcium silicate layer obtained in condition II had a more porous structure than that in condition I (Figures 4 and 5), since a fast gelation rate gives an open structure. ${ }^{35}$ These results are in agreement with the ones obtained from FT-IR [Figure 1(a,b)] where the intensity of Si-O-Si band was very high for the calcium silicate under the condition II. Related with the apatite nucleation, it has been demonstrated $^{31,32,36}$ that the porous structure in the silica gels favors the induction of apatite layer. If pores are assumed as a nucleation sites, the ionic concentration inside the pores is higher than at any other part of the surface, and the degree 
of supersaturation required for heterogeneous nucleation is more likely to occur inside the pore. This was reported by Hench and coworkers. ${ }^{36}$ As result, the calcium silicate layer formed in condition II dissolved into SBF more rapidly than that formed in condition I, and hence the induction time for apatite formation is reduced. From the ICP results in Figure 7 , it was shown that the release of silicon was higher for the condition II than for the condition I due to the porosity present in the calcium silicate coating. The release of silicon is attributed to the dissolution of silicon ions from the calcium silicate layer, which results in a formation of the $\mathrm{Si}-\mathrm{OH}$ groups. These groups are responsible for the apatite nucleation. The amount of these groups can be speculated by the rate of the dissolution of the silica into the SBF, because the dissolution of the silica gel, in this case calcium silicate gel, proceeds via hydrolysis of the silica. ${ }^{22,37}$

Furthermore, these results indicate that besides the presence of a relatively high density of $\mathrm{Si}-\mathrm{OH}$ on the microspheres surface, the structure of calcium silicate layer is a prerequisite for apatite formation in the body environment, in which depends on method of preparation, greatly affects the nucleation rate. The induction time for apatite nucleation decreases with a porous structure, since the number of nucleation of sites, defined by the textural characteristics of the coating, and the diffusion of the ions into the pores might control the nucleation rate. ${ }^{36}$

When the calcium silicate-coated microspheres were soaked in SBF, the calcium ions in the calcium silicate layer were released into $\mathrm{SBF}$ to form many $\mathrm{Si}-\mathrm{OH}$ groups and simultaneously increased the ionic activity product of the surrounding fluid with respect to apatite. The $\mathrm{Si}-\mathrm{OH}$ groups induced the apatite nucleation, and the increased ionic activity product accelerates the nucleation rate of apatite. Once apatite nuclei are formed, they can spontaneously grow into a uniform layer by consuming the calcium and phosphate ions from the SBF, since SBF is already highly supersaturated with respect to apatite. ${ }^{38}$ This is supported by the results obtained by the measurements of calcium and phosphorus concentrations of SBF shown in the Figure 7. These bioactive microspheres may be useful for bone tumors as well as for bone repair and at same time release an antibiotic in situ for treatment and prevention of bone infection associating the osteoconductivity of the material. Therefore, combining the properties of these microspheres, it is possible to have a material that can act as a two in one-repair and release - that would eventually augment a range of folds in the repair/regeneration and ultimately, improves quality of life of the patient. Moreover, the obtained microspheres can be used for further scaffold production by means of applying a particle aggregation processing route, into particular shapes and with defined pore sizes, for bone tissue engineering.

\section{CONCLUSIONS}

A uniform apatite layer could be successfully formed in SBF within 1 day on polyamide 12 , magnetite-containing polyam- ide 12 and EVOH microspheres, when they were previously treated with calcium silicate solution under the condition II. Moreover, it was shown that a calcium silicate layer, with a porous structure, rich in calcium ions and $\mathrm{Si}-\mathrm{OH}$ groups, was able to be formed on the microspheres by the present method and has the ability to induce the formation of an apatite layer. The resultant microspheres with apatite-forming ability are a very promising material to be used in the bone repair and regeneration field. Finally, it is worth to state that this work is one of the first reports on the coating of microspheres with biomimetic calcium-phosphate layers.

I. B. Leonor thanks the Portuguese Foundation for Science and Technology (FCT) for providing her a PhD scholarship.

\section{REFERENCES}

1. Hench LL. Biomaterials: A forecast for the future. Biomaterials 1998;19:1419-1423.

2. Posner AS. The mineral of bone. Clin Orthop Relat Res 1985; 200:87-99.

3. El-Ghannam A. Bone reconstruction: From bioceramics to tissue engineering. Expert Rev Med Devices 2005;2:87-101.

4. Davies JE, Baldan N. Scanning electron microscopy of the bone-bioactive implant interface. J Biomed Mater Res 1997; 36:429-440.

5. Bajpai PK, Benghuzzi HA. Ceramic systems for long-term delivery of chemicals and biologicals. J Biomed Mater Res 1988;22:1245-1266.

6. Sivakumar M, Panduranga Rao K. Preparation, characterization and in vitro release of gentamicin from coralline hydroxyapatite-gelatin composite microspheres. Biomaterials 2002;23:3175-3181.

7. Ragel CV, Vallet-Regi M. In vitro bioactivity and gentamicin release from glass-polymer-antibiotic composites. J Biomed Mater Res 2000;51:424-429.

8. Sivakumar M, Manjubala I, Rao KP. Preparation, characterization and in-vitro release of gentamicin from coralline hydroxyapatite-chitosan composite microspheres. Carbohydr Polym 2002;49:281-288.

9. Nobs L, Buchegger F, Gurny R, Allemann E. Surface modification of poly(lactic acid) nanoparticles by covalent attachment of thiol groups by means of three methods. Int J Pharm 2003;250:327-337.

10. Kim H-W, Yoon B-H, Kim H-E. Microsphere of apatite-gelatin nanocomposite as bone regenerative filler. J Mater Sci: Mater Med 2005;16:1105-1109.

11. Quaglia F, Ostacolo L, Nese G, De Rosa G, La Rotonda MI, Palumbo R, Maglio G. Microspheres made of poly(e-caprolactone)-based amphiphilic copolymers: Potential in sustained delivery of proteins. Macromol Biosci 2005;5:945-954.

12. Wu TJ, Huang $\mathrm{HH}$, Lan CW, Lin CH, Hsu FY, Wang YJ. Studies on the microspheres comprised of reconstituted collagen and hydroxyapatite. Biomaterials 2004;25:651-658.

13. Silva GA, Costa FJ, Coutinho OP, Radin S, Ducheyne P, Reis RL. Synthesis and evaluation of novel bioactive composite starch/bioactive glass microparticles. J Biomed Mater Res A 2004;70:442-449.

14. Silva GA, Costa FJ, Neves NM, Coutinho OP, Dias AC, Reis RL. Entrapment ability and release profile of corticosteroids from starch-based microparticles. J Biomed Mater Res A 2005;73:234-243.

15. Silva GA, Coutinho OP, Ducheyne P, Shapiro IM, Reis RL. The effect of starch and starch-bioactive glass composite 
microparticles on the adhesion and expression of the osteoblastic phenotype of a bone cell line. Biomaterials 2007;28: 326-334.

16. Ebisawa Y, Miyaji F, Kokubo T, Ohura K, Nakamura T. Bioactivity of ferrimagnetic glass-ceramics in the system $\mathrm{FeO}$ Fe2O3-CaO-SiO2. Biomaterials 1997;18:1277-1284.

17. Ikenaga M, Ohura K, Yamamuro $\mathrm{T}$, Kotoura Y, Oka M, Kokubo T. Localized hyperthermic treatment of experimental bone tumors with ferromagnetic ceramics. J Orthop Res 1993; 11:849-855.

18. Ang KL, Venkatraman S, Ramanujan RV. Magnetic PNIPA hydrogels for hyperthermia applications in cancer therapy. Mater Sci Eng C 2007;27:347-351.

19. Kawashita M, Tanaka M, Kokubo T, Inoue Y, Yao T, Hamada S, Shinjo T. Preparation of ferrimagnetic magnetite microspheres for in situ hyperthermic treatment of cancer. Biomaterials 2005;26:2231-2238.

20. Ruiz-Hernández E, Serrano MC, Arcos D, Vallet-Regí M. Glass-glass ceramic thermoseeds for hyperthermic treatment of bone tumors. J Biomed Mater Res 2006;79A:533-543.

21. Kokubo T, Kushitani H, Sakka S, Kitsugi T, Yamamuro T. Solutions able to reproduce in vivo surface-structure changes in bioactive glass-ceramic A-W. J Biomed Mater Res 1990; 24:721-734.

22. Li P, Ohtsuki C, Kokubo T, Nakanishi K, Soga N, Nakamura T, Yamamuro T. Process of formation of bone-like apatite layer on silica-gel. J Mater Sci: Mater Med 1993;4:127-131.

23. Li PJ, Ohtsuki C, Kokubo T, Nakanishi K, Soga N, Nakamura $\mathrm{T}$, Yamamuro T. Apatite formation induced by silica-gel in a simulated body-fluid. J Am Ceram Soc 1992;75:2094-2097.

24. Oyane A, Kawashita M, Nakanishi K, Kokubo T, Minoda M, Miyamoto T, Nakamura T. Bonelike apatite formation on ethylene-vinyl alcohol copolymer modified with silane coupling agent and calcium silicate solutions. Biomaterials 2003;24:1729-1735.

25. Bertoluzza A, Fagnano C, Morelli MA, Gottardi V, Guglielmi M. Raman and infrared-spectra on silica-gel evolving toward glass. J Non-Cryst Solids 1982;48:117-128.

26. Almeida RM, Guiton TA, Pantano CG. Characterization of silica gels by infrared reflection spectroscopy. J Non-Cryst Solids 1990;121(1-3):193.
27. Fidalgo A, Ilharco LM. The defect structure of sol-gel-derived silica/polytetrahydrofuran hybrid films by FTIR. J Non-Cryst Solids 2001;283(1-3):144-154.

28. Fidalgo A, Ilharco LM. Thickness, morphology, and structure of sol-gel hybrid films. I. The role of the precursor solution's aging. J Sol-Gel Sci Technol 2003;26:363-367.

29. Koutsopoulos S. Synthesis and characterization of hydroxyapatite crystals: A review study on the analytical methods. J Biomed Mater Res 2002;62:600-612.

30. Cho SB, Kokubo T, Nakanishi K, Soga N, Ohtsuki C, Nakamura T, Kitsugi T, Yamamuro T. Dependence of apatite formation on silica gel on its structure: Effect of heat treatment. J Am Ceram Soc 1995;78:1769-1774.

31. Cho SB, Miyaji F, Kokubo T, Nakanishi K, Soga N, Nakamura T. Apatite formation on silica gel in simulated body fluid: Effects of structural modification with solvent-exchange. J Mater Sci: Mater Med 1998;9:279-284.

32. Cho SB, Nakanishi K, Kokubo T, Soga N, Ohtsuki C, Nakamura T. Apatite formation on silica gel in simulated body fluid: Its dependence on structures of silica gels prepared in different media. J Biomed Mater Res 1996;33:145-151.

33. Li P, Nakanishi K, Kokubo $\mathrm{T}$, de Groot K. Induction and morphology of hydroxyapatite, precipitated from metastable simulated body fluids on sol-gel prepared silica. Biomaterials 1993;14:963-968.

34. Brinker CJ, Scherer GW. Sol-Gel Science-The Physics and Chemistry of Sol-Gel Processing. San Diego: Academic Press; 1990.

35. Vansant EF, Van Der Voort P, Vrancken KC. Characterization and Chemical Modification of the Silica Surface. Amsterdam: Elsevier; 1995.

36. Pereira MM, Clark AE, Hench LL. Effect of texture on the rate of hydroxyapatite formation on gel-silica surface. J Am Ceram Soc 1995;78:2463-2468.

37. Li P, Ye X, Kangasniemi I, de Blieck-Hogervorst JM, Klein $\mathrm{CP}$, de Groot $\mathrm{K}$. In vivo calcium phosphate formation induced by sol-gel-prepared silica. J Biomed Mater Res 1995;29:325328.

38. Kim H-M. Bioactive ceramics: Challenges and perspectives. J Ceram Soc Jpn 2001;109:S49-S57. 